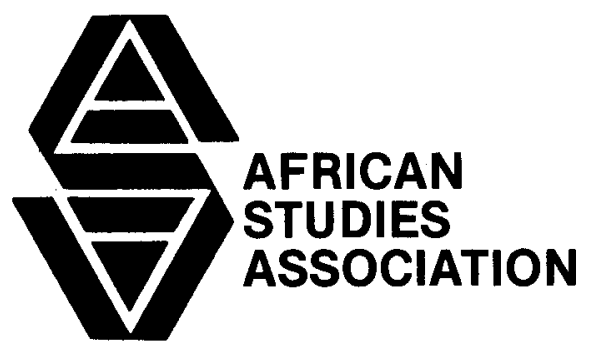

ASA News, Vol. XVI No. 1, JANUARY/MARCH, 1983. Editors: Eddie J. Huckaby and Donald Cosentino. Published quarterly by the African Studies Association. Contributions should be sent to $A S A$ News, 255 Kinsey Hall, UCLA, Los Angeles, CA 90024. All ASA individual and institutional members receive $A S A$ News, Issue and the African Studies Review, which includes the former $A S A$ Review of Books. Domestic claims for non-receipt of issues must be made within six months of the month of publication-overseas claims must be made within one year.

\title{
AFRICAN STUDIES ASSOCIATION
}

255 Kinsey Hall

University of California, Los Angeles

Los Angeles, California 90024

Non Profit

U.S. Postage

PAID

Los Angeles, CA.

Permit 12378 